Lens proteins

\section{More molecular opportunism}

\author{
Russell F. Doolittle
}

THE morphological resemblance of cephalopod eyes to those of vertebrates has long been considered a fascinating case of anatomical convergence (see figure), as it is well known that image-forming eyes have evolved independently on several occasions. In cephalopod and vertebrate eyes, for example, the cells in the retina are organized in completely different ways. It is known that the vertebrate eye's lens indulges in a kind of genetic piracy, and on page 86 of this issue', Tomarev and Zinovieva confirm that the cephalopod lens is guilty of a similar offence - the enslavement of an enzyme for a structural role. Lenses are found in other animal visual systems besides cephalopods and vertebrates, of course, including other molluses (gastropods), spiders, polychaet worms, flatworms and even coelenterates ${ }^{2}$. It will be of great interest to find out if those transparent structures have also pirated enzymes for structural purposes.

The bizarre story of the evolution of lens proteins began in 1982 with the report $^{3}$ that $\alpha$-crystallin, the predominant protein in the lenses of most vertebrate eyes, is similar to small heat-shock proteins. These heat-shock proteins are now known to be common among all eukaryotes and other types of structural proteins, including a schistosomal eggcase protein ${ }^{4}$, are also thought to be descended from them. The small heat-shock proteins could also be related to the ubiquitous 'prosome', an unusually stable ribonucleoprotein'. Further, the $\beta \gamma$-crystallins, the other most common set of lens proteins, have structural features in common with a bacterial spore coat protein ${ }^{6}$, which implies that they too may be ancient.

The real surprise came when a routine computer search revealed that the aminoacid sequences of $\delta$-crystallin from bird lenses and the enzyme argininosuccinate lyase are more than 55 per cent identical (see table). At about the same time, it was found that $\varepsilon$-crystallin, a protein of the lenses of birds and reptiles, is the active

Enzymes corresponding to various types of lens crystallin

\begin{tabular}{lcl}
\hline Enzyme & Crystallin & Occurrence \\
Argininosuccinate lyase & $\delta$ & Birds \\
Lactate dehydrogenase & $\varepsilon$ & Birds \\
& & Reptiles \\
Aldose reductase & $\varrho$ & Amphibians \\
Enolase & $\tau$ & Birds \\
& & Reptiles \\
Glutathione S-transferase & $\mathrm{S}$ & Fish \\
\hline
\end{tabular}

glycolytic enzyme lactate dehydrogenase? The $\varrho$-crystallin from frog lenses was then shown $^{8}$ to be about 50 per cent identical with human liver aldehyde reductase and the rat lens enzyme aldose reductase, and turtle $\tau$-crystallin shows a remarkably close match to the enzyme enolase.

Even more surprising, a computer search of a published sequence fragment from a squid lens crystallin suggested ${ }^{9}$ that this protein might be the enzyme glutathione S-transferase. It is this suggestion a

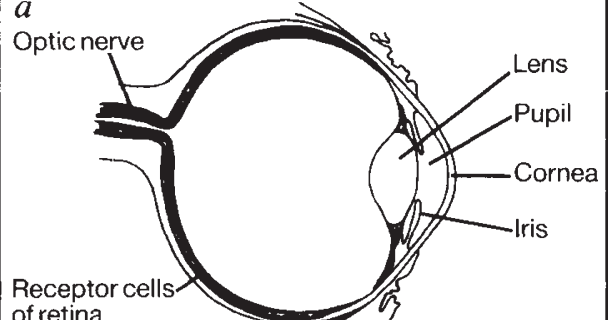
of retina

\section{$b$}

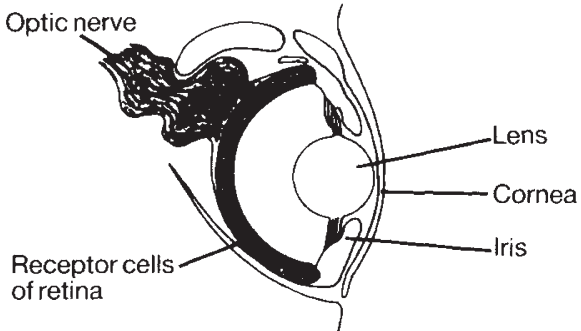

Comparison of $a$, vertebrate (human) and $b$, cephalopod (squid) eyes (from ref. 12).

that Tomarev and Zinovieva confirm in their paper in this issue'. These authors cloned a family of squid lens proteins and show that the inferred amino-acid sequences of two of them are very similar to mammalian glutathione S-transferase.

What is to be made of these data? It is not news, of course, that old proteins can be duplicated and adapted to new functions. Well-known examples include the blood plasma protein haptoglobin, which has descended from the serine proteases, and the milk protein lactalbumin, which is derived from the enzyme lysozyme. The continuous expansion of the inventory of enzymes and other proteins is generally thought to follow from gene duplications and subsequent modification by base replacement. Certainly, the history of $\alpha$ - and $\beta \gamma$ crystallins fits this scheme.

But the case of enzyme recruitment by the lens seems to be different. Piatigorsky et al. recently showed ${ }^{10}$ that the protein being over-expressed in the avian embryonic lens is argininosuccinate lyase itself and not a duplicated congener, and the same case has just been made by Hendriks et al. " for lactate dehydrogenase and duck $\varepsilon$-crystallin. The same situation could be true of other enzyme-crystallin systems. The degree of sequence similarity observed for some of the systems seems lower than expected for single-copy active enzymes, however, given the phylogenetic situation of the species involved. Although an amphibian enzyme might be expected to be more than 75 per cent identical with its mammalian counterpart, the frog lens $\varrho$-crystallin is only about 50 per cent identical with mammalian aldose or aldehyde reductases ${ }^{8}$. Frog and mammalian cytochromes $c$ are more than 80 per cent identical, for example, and even their haemoglobin $\alpha$-chains are more than 55 per cent identical. Similarly, a typical molluscan enzyme ought to be greater than 50 per cent identical in sequence to the corresponding mammalian enzyme, but the squid crystallins are only about 25 per cent identical with the mammalian glutathione S-transferase. The latter case is complicated in that this dimeric enzyme actually comprises a family of subunit types, as apparently do the squid lens proteins.

It seems unlikely that these enzymes are present in the lens for metabolic reasons. So why should they have a structural role in the lens? Crystallins are well known to be water-soluble proteins that can pack together efficiently to form very large molecular aggregates, and it could be that the only requirement for a structural lens protein is for a globular protein that can pack well and form transparent aggregates.

Or, as Piatigorsky et al. suggest ${ }^{10}$, maybe it has to do with an aspect of gene regulation that allows for tissue-specific expression of certain metabolic enzymes, and one that can be overcome in a tissue like the lens. Whatever it is, the independently evolved molluscan system has obviously hit on the same strategy. What has long been regarded as a model of anatomic convergence now also appears to involve a convergence of genetic enterprise.

1. Tomarev, S. I. \& Zinovieva, R. D. Nature 336, 86-88 (1988).

2. Wells. M. Lower Animals (World University Library, New York, 1968)

Ingolia, T.D. \& Craig, E.A. Proc. natn. Acad. Sci. U.S.A 79, 2360-2364 (1982)

4. de Jong. W.W. et al. J. biol. Chem. 263. 5151-5149 (1988)

5. Martins de Sa, C. et al. J. molec, Biol. 187, 479-493 (1986)

6. Wistow, G., Summers, L. \& Blundell, T. Nature 315, 771 773 (1985).

7. Wistow, G.. Mulders, J.W.M. \& de Jong. W.W. Nature 326, 622-624 (1987)

Carper, D. et al. FEBS Lett. 220, 209-213 (1987)

9. Wistow, G. \& Piatigorsky, J. Science 236, 1554-1556 (1987).

10. Piatigorsky, J. et al. Proc. natn. Acad. Sci. U.S.A. 85 3479-3483 (1988)

11. Hendriks, W. et al. Proc. natn. Acad. Sci. U.S. A. 85, 7114 $7118(1988)$.

12. Purves, W.K. \& Orians, G.H. Life, the Science of Biology (Grant. 1983)

Russell F. Doolittle is at the Center for Molecular Genetics, University of California, San Diego, La Jolla, California 92093, USA. 